\title{
Investigation of Rheological Properties of Blended Cement Pastes Using Rotational Viscometer and Dynamic Shear Rheometer
}

\author{
Yoo Jae Kim $\mathbb{D},{ }^{1}$ Bum-Yean Cho, ${ }^{2}$ Soon-Jae Lee $\mathbb{D},{ }^{1}$ Jiong $\mathrm{Hu}^{3}$ and James W. Wilde \\ ${ }^{1}$ Department of Engineering Technology, Texas State University, 601 University Drive, San Marcos, TX 78666, USA \\ ${ }^{2}$ Department of Architectural Engineering, University of Seoul, 163 Seoulsiripdae-ro, Dongdaemun-gu, Seoul 02504, \\ Republic of Korea \\ ${ }^{3}$ Department of Civil Engineering, University of Nebraska-Lincoln, 1400 R Street, Lincoln, NE 68588, USA
}

Correspondence should be addressed to Yoo Jae Kim; yk10@txstate.edu

Received 4 December 2017; Revised 16 December 2017; Accepted 25 December 2017; Published 8 February 2018

Academic Editor: João M. P. Q. Delgado

Copyright (c) 2018 Yoo Jae Kim et al. This is an open access article distributed under the Creative Commons Attribution License, which permits unrestricted use, distribution, and reproduction in any medium, provided the original work is properly cited.

\begin{abstract}
To successfully process concrete, it is necessary to predict and control its flow behavior. However, the workability of concrete is not completely measured or specified by current standard tests. Furthermore, it is only with a clear picture of cement hydration and setting that full prediction and control of concrete performance can be generalized. In order to investigate the rheological properties of blended cement pastes, a rotational viscometer (RV) was used to determine the flow characteristics of ordinary and blended pastes to provide assurance that it can be pumped and handled. Additionally, a dynamic shear rheometer (DSR) was used to characterize both the viscous and elastic components of pastes. Ordinary Portland cement paste and blended pastes (slag, fly ash, and silica fume) were investigated in this study. The stress and strain of the blended specimens were measured by the DSR, which characterizes both viscous and elastic behaviors by measuring the complex shear modulus (the ratio of total shear stress to total shear strain) and phase angle (an indicator of the relative amounts of recoverable and nonrecoverable deformation) of materials. Cement pastes generally exhibit different rheological behaviors with respect to age, mineral admixture type, and cement replacement level.
\end{abstract}

\section{Introduction}

The concrete industry defines workability as "the ease and homogeneity for which the concrete or mortar can be placed, consolidated, and finished" [1]. Concrete workability should ideally be characterized by its rheological properties, thus establishing a materials science basis. Cement paste plays a major role in controlling rheological properties, making it necessary to simulate the workability of concrete before it is transported and handled. However, there are no standard tests for fresh concrete that relate directly to plastic viscosity $[2,3]$. Because of this, the workability of concrete is not completely measured or specified by current standard tests [4].

The flow behavior of cement paste is important because it controls the flow ability and process ability of concrete. Because the viscosity of cement paste rises with increasing concentration of solid particles, several empirical relationships between viscosity, cement concentration, and fineness have been proposed [5].
It is important to determine the setting time when testing paste specimens. As setting is significant in the development of rigidity in an initially fluid material, it is a part of rheology and the study of flow [6]. Plastic viscosity depends mainly on the volume of solid particles and how densely they are packed. The microstructure most commonly responsible for high yield stress is the threedimensional network that often forms due to flocculation. The yield stress reflects the extent of this flocculation and the strength of the attractive interparticle forces responsible for the flocculation [7].

Hydration reactions tend to influence the viscosity results of ordinary and blended pastes because hydration generally increases both yield stress and plastic viscosity. Hydration mostly increases plastic viscosity only insofar as it increases the volume fraction of solid material [8]. Yield stress is particularly sensitive to hydration reactions, and since early hydration products cause cement particles to bond more strongly together (or increase the number of 
interparticle bonds), hydration is expected to increase the yield stress [9].

In order to measure the viscosity of the blended pastes in this study, the rotational viscometer was used to determine the flow characteristics of ordinary and blended pastes and to assure that it could be pumped and handled. While a viscometer is designed to test the asphalt binder viscosity, it was used in this study to compare the viscous property of the different blended pastes at a temperature of $25^{\circ} \mathrm{C}$ since the temperature effects the rheological properties of the cement paste [10]. The stress and strain of the blended specimens were measured with a dynamic shear rheometer (DSR), which characterizes both viscous and elastic behavior by measuring the complex shear modulus (the ratio of total shear stress to total shear strain) and phase angle (an indicator of the relative amounts of recoverable and nonrecoverable deformation) of materials.

\section{Experimental Program}

2.1. Materials and Equipment. Three supplementary cementing materials (SCMs) and one Portland cement source were used in this research project. The fly ash was a class $\mathrm{C}$ ash from Boral Material Technologies, and the ground granulated blast furnace slag was furnished by Holcim. The silica fume was densified microsilica from Grace Construction Products, and the Type I Portland cement was furnished by LaFarge Building Materials.

Cement pastes were mixed and tested using the following equipment: (1) a Cole-Parmer servodyne mixer with a high shear mixing blade to mix the paste samples, (2) paste samples were tested for rotational viscosity with a Brookfield model DV-II+ viscometer, and (3) dynamic shear rheometry testing was performed with a Bohlin Instruments rheometer.

2.2. Sample Preparation. Paste samples were prepared by first batching the appropriate amounts of Portland cement and mineral admixture. For all testing, the weight of cementitious material used was 80 grams. Both fly ash and slag were added at dosage rates of $20 \%, 30 \%$, and $40 \%$, while silica fume was added at lower dosage rates of 5\%, 10\%, and $15 \%$. DSR testing was performed with a w/c ratio of 0.40 , while rotational viscosity testing was performed at $\mathrm{w} / \mathrm{c}$ ratios of 0.40 and 0.50 . Before the addition of water to the blend, the cementitious material was first mixed by hand to provide uniformity.

Upon the addition of water, the paste was mixed by hand for approximately 15 seconds to remove excess air and allow for the mixing water to reach the bottom of the container. The paste was then immediately mixed using the servodyne mixer with a high shear mixing blade for 1 minute at a speed of 300 RPM. This allowed for complete mixing without any visible clumps in the paste. After mixing, DSR or viscosity testing was performed on the paste samples.

2.3. Rotational Viscometer. The rotational viscometer is normally used to measure the flow characteristics of asphalt binders. For this project, however, the viscometer was used to measure the flow characteristics of cement pastes. The viscometer operates by rotating a spindle inside the
TABLE 1: Specific gravities for cementitious materials.

\begin{tabular}{lc}
\hline Material & Specific gravities \\
\hline Portland cement & 3.15 \\
Silica fume & 2.20 \\
Slag & 2.90 \\
Fly ash & 2.40 \\
\hline
\end{tabular}

specimen test tube and measuring the torque required to rotate the spindle at a given speed, normally 20 RPM. Based on the torque, the viscometer determines the viscosity of the specimen in units of centipoises $(\mathrm{cP})$.

There are two components for the rotational viscosity apparatus: a temperature control system and a viscosity measuring system. The temperature control system consists of a thermocontainer and temperature controller. The specimen is placed in an aluminum test tube, which is then placed into the thermocontainer. For asphalt binder testing, the test temperature is maintained at either $135^{\circ} \mathrm{C}$ or $165^{\circ} \mathrm{C}$. Since such high temperatures would be very detrimental to cement paste, the temperature was set to $25^{\circ} \mathrm{C}$ for testing paste specimens. The viscosity measuring system consists of a motor, spindle, control keys, and digital readout. As the spindle spins inside the specimen, a torsional spring is wound as the torque required to rotate the spindle increases.

The spindle's shape is best described as a "plumb bob." Different-sized spindles are available, depending on the specimen that is being tested. For this work, a size 27 spindle was utilized, which is typical for modified asphalt binders. When using this size spindle for testing asphalt binders, a sample size of 8.5 grams was used. Since an asphalt binder was not used, certain assumptions had to be made to ensure that the appropriate volume of paste was placed in the test tube. Since the specific gravity of asphalt binder is roughly 1.030 , a sample size of 8.5 grams of asphalt binder would yield a volume of $8.25 \mathrm{~cm}^{3}$. When performing calculations to determine the weight of cement paste to add to the test tube to obtain a volume of $8.25 \mathrm{~cm}^{3}$, specific gravities of the materials used were assumed, as was an air void content of zero percent. Table 1 illustrates the specific gravities used for the calculations.

Sample calculations are shown below for determining the weight of cement paste to test for rotational viscosity.

For $20 \%$ fly ash, w/c $=0.50$, and SG of water

$$
\begin{aligned}
= & 1.00, \text { combined SG }:[(0.5)(1.00) \\
& +(0.20)(2.40)+(0.80)(3.15)] / 1.5 \\
= & 2.333, \text { weight }=\mathrm{SG}^{*} \text { volume } \\
= & 2.333^{*} 8.25 \mathrm{~cm}^{3}=19.2 \text { grams. }
\end{aligned}
$$

For 30\% slag, w/c $=0.50$, and SG of water

$$
\begin{aligned}
= & 1.00, \text { combined } \mathrm{SG}:[(0.5)(1.00) \\
& +(0.30)(2.90)+(0.70)(3.15)] / 1.5 \\
= & 2.383, \text { weight }=\mathrm{SG}^{*} \text { volume } \\
= & 2.383^{*} 8.25 \mathrm{~cm}^{3}=19.7 \text { grams. }
\end{aligned}
$$




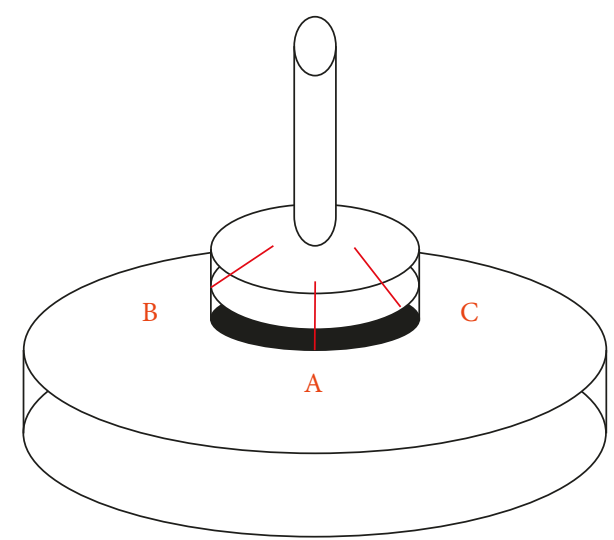

Figure 1: Dynamic shear rheometer operation.

The paste specimens were added to the test tube upon completion of mixing. It should be noted that it was difficult to obtain the exact amount of paste in the test tube due to the thickness of the paste. Once the specimen was loaded into the test tube, it was placed into the thermocontainer. The spindle was then lowered into the test tube, and the test began. Viscosity testing for asphalt binders requires only three measurements (one measurement every minute for three minutes). For the cement paste samples, testing was performed for 30 minutes with the viscometer recording the data every minute.

2.4. Dynamic Shear Rheometer. The dynamic shear rheometer (DSR) is used to characterize both the viscous and elastic components of asphalt binders. The DSR is able to do this by applying shear stress to the sample. Shear stress is applied by placing a fixed plate below the sample and an oscillating plate above the sample. The DSR was programmed to operate at a frequency of 10 radians per second or approximately $1.59 \mathrm{~Hz}$ (cycles per second). During each cycle, the centerline of the top plate passed from point $A$ to point $B$ (Figure 1). From point B, the top plate rotated to point $C$ after passing point $\mathrm{A}$. The cycle was completed when the top plate returned to point $\mathrm{A}$ from point $\mathrm{C}$ [11].

For an asphalt binder sample, a silicone mold is used to form a disc-shaped specimen. The use of this mold is impractical for a cement paste sample because the paste would have to set before it could be removed and maintain the proper shape. As a result, the paste samples were placed directly onto the fixed plate and shaped with a spatula. Paste samples were tested using a 2000 micron gap spacing between the two plates. The gap spacing was originally set to 2050 microns, and the samples were "trimmed." After trimming, the gap spacing was set to 2000 microns. Tests with the DSR are normally conducted at the high-temperature grade of an asphalt binder, but for this testing, the temperature was maintained at $25^{\circ} \mathrm{C}$.

The results of DSR testing are the complex shear modulus $\left(\mathrm{G}^{*}\right)$ and phase angle $(\delta)$. The shear modulus is a measure of the materials resistance to deformation when tested under repeated shear stress. This shear modulus has both a viscous and elastic component, and the relative

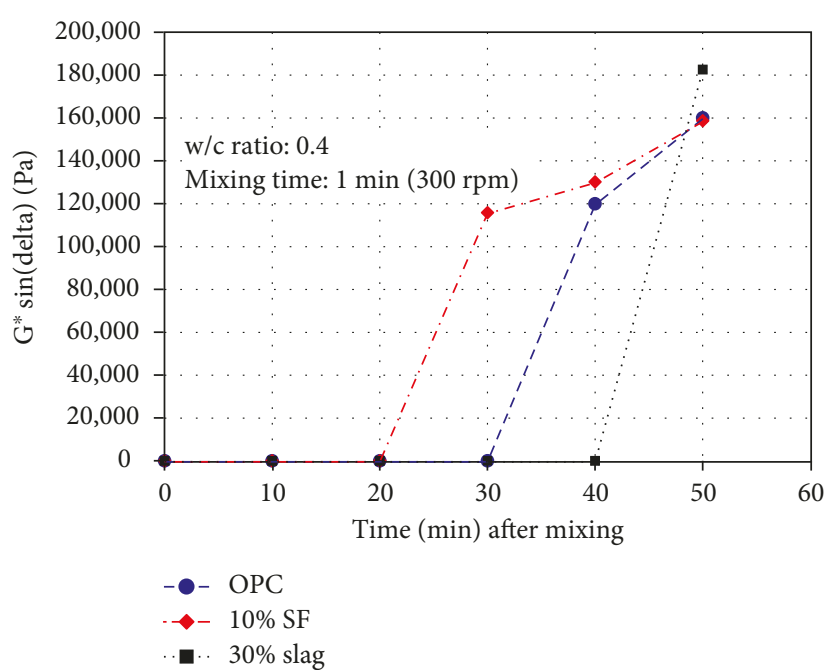

Figure 2: $\mathrm{G}^{*} \sin ($ delta) with time after mixing $(0.4 \mathrm{w} / \mathrm{c}$ ratio).

amounts of each are determined by the phase angle. A sample with a phase angle of $90^{\circ}$ would be characterized as a completely viscous material. Likewise, a sample with a phase angle of $0^{\circ}$ would be classified as a completely elastic material. For asphalt binders, temperature and aging conditions are the two main properties that change the shear modulus and phase angle. For cement pastes, time is the main factor that can change the results. As a cement paste begins to harden, its behavior should change from more viscous to more elastic.

During this research, paste samples were originally left between the two plates of the DSR, with testing occurring at various time intervals. This method of testing, while adequate for asphalt binder samples, did not work well for paste samples. The prolonged time between the two plates caused the paste to dry out. This probably occurred due to either the thickness of the paste sample (2000 microns) or from the constant pressure applied to the sample by the plates or a combination of both. It was determined that the best method for testing the paste over time was to test an individual sample only once. For the different time periods investigated, a new sample was obtained from the mixing container, as the paste remained fluid for a much longer time in the mixing container. Upon testing paste samples made with a $\mathrm{w} / \mathrm{c}$ ratio of 0.40 , there was a noticeable discoloration on the bottom plate of the DSR.

\section{Results and Discussion}

3.1. Dynamic Shear Rheometer. As expected, differences in DSR data were observed for the various mineral admixtures. Figure 2 illustrates the viscous modulus at the midvalues of the mineral admixture content. The efficiency of the admixture types in terms of early hydration occurred in the following sequence: $10 \%$ SF (the cement paste with $10 \%$ silica fume) $>$ OPC (the cement paste with no admixture) $>30 \%$ slag (the cement paste with $30 \%$ slag). The DSR results confirmed what was expected in that the silica fume blended paste reacted more quickly 


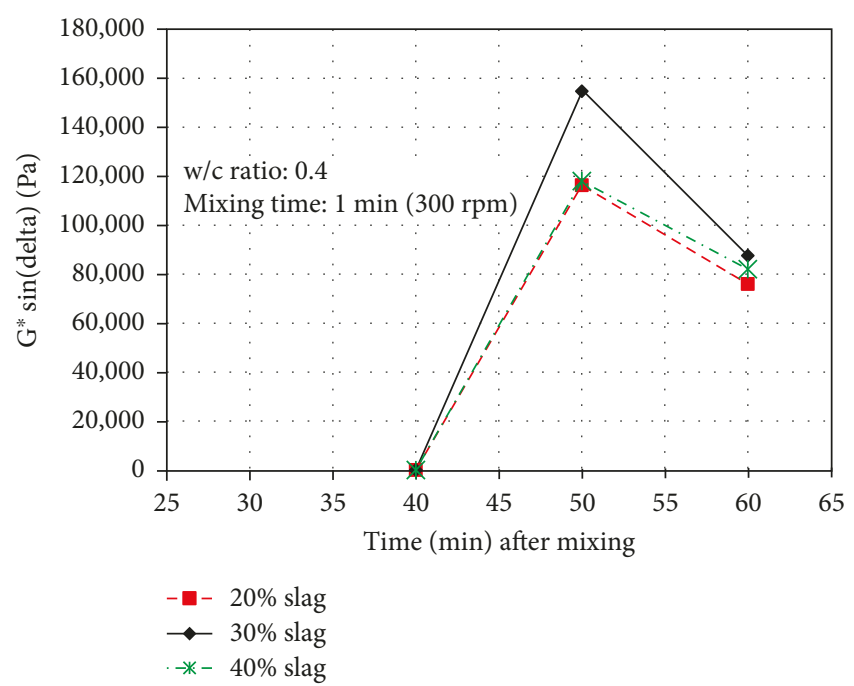

Figure 3: $\mathrm{G}^{*} \sin ($ delta $)$ with slag content $(0.4 \mathrm{w} / \mathrm{c}$ ratio).

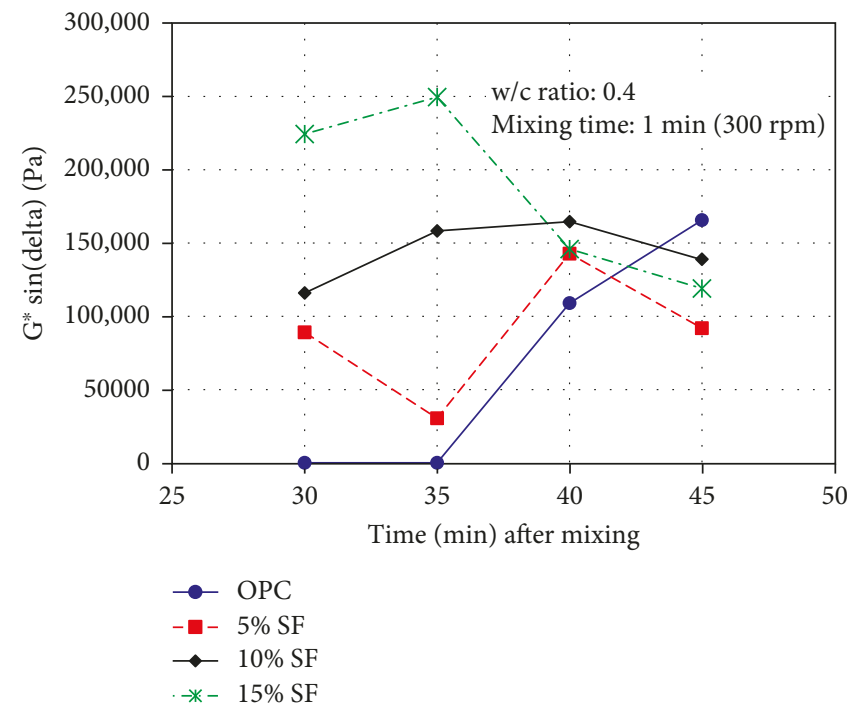

Figure 4: $\mathrm{G}^{*} \sin ($ delta) with silica fume content $(0.4 \mathrm{w} / \mathrm{c}$ ratio).

than the control, which reacted faster than the slag blended paste.

Fly ash data for the DSR are not shown due to variations in the testing technique. The cement pastes containing fly ash were tested in a slightly different manner than the other types of cement paste. Once this difference was noticed, it was determined that the cement pastes should not be tested in the DSR due to discoloration of the base plate. For the fly ash samples, as with the silica fume and slag, it was difficult to find a trend with varying fly ash replacement levels.

It is assumed that the effects of admixtures are linearly dependent on the admixture content. Even if this is not true in all cases, it is expected that there is a significant relationship with admixture content. DSR test results with 3 different slag contents are shown in Figure 3. Using the DSR, it was difficult to find any trend when varying the

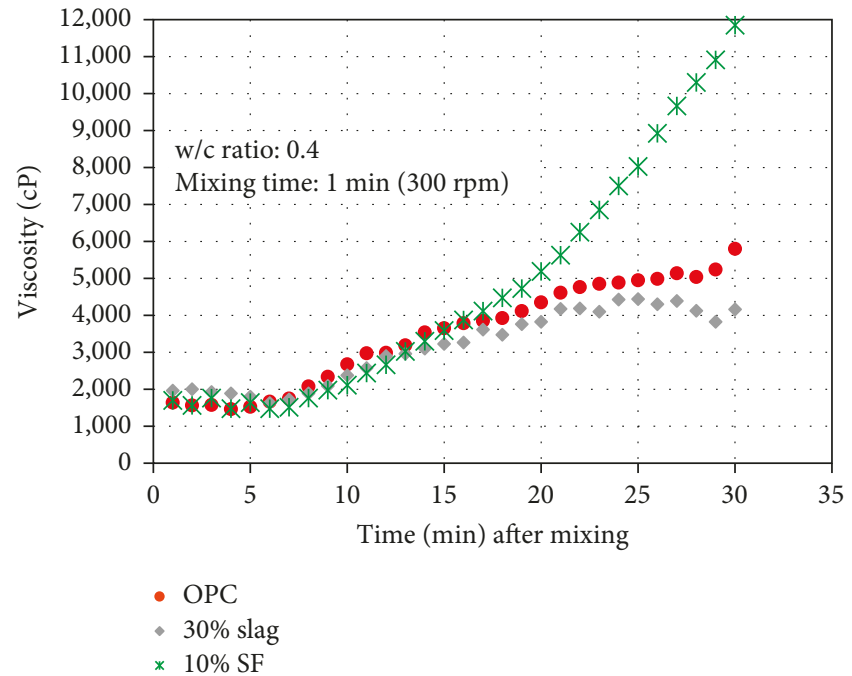

FIGURE 5: Viscosity with time after mixing $(0.4 \mathrm{w} / \mathrm{c}$ ratio).

slag content. It was expected that the viscous modulus would decrease with increased levels of slag due to the latent hydraulic nature and high fineness of slag. Possible reasons for these variations are that the DSR is originally designed to measure the rheological properties of asphalt binders at intermediate and high temperatures. In this study, however, the rheological properties of cement pastes were measured at $25^{\circ} \mathrm{C}$.

3.1.1. Tester Technique. After considerable trial and error, the application of the DSR with cement pastes was found to be possible. However, there was no fixed method to follow, and several experimental errors could be a reason for the irregular trends.

DSR test results with 3 different silica fume contents are shown in Figure 4. Similar to slag, no trend was found in the cement paste with different silica fume contents. For the 


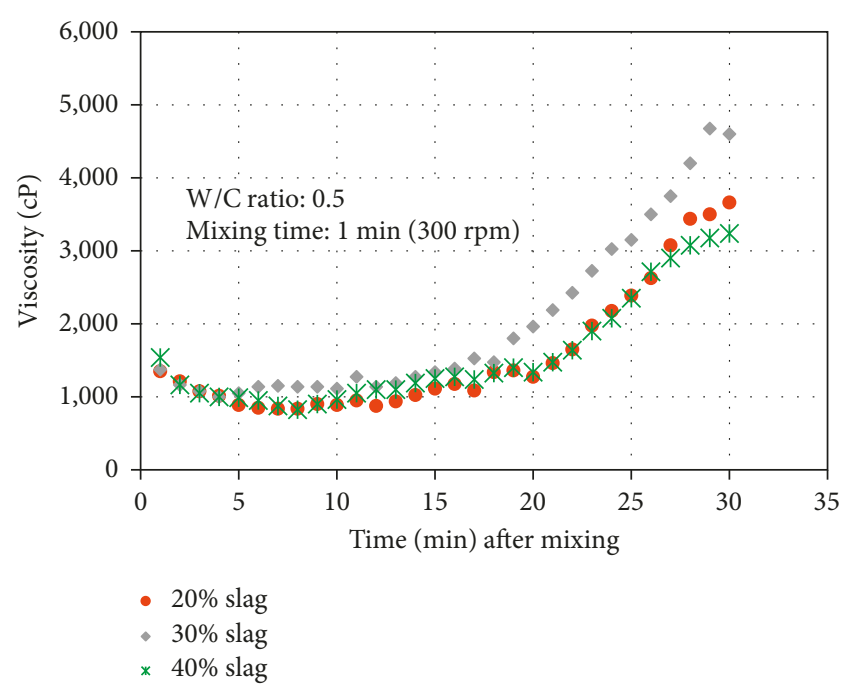

Figure 6: Viscosity with slag content $(0.5 \mathrm{w} / \mathrm{c}$ ratio).

silica fume, it was expected that increased amounts of silica fume would increase the viscous modulus.

3.2. Rotational Viscometer. Variations in hydration reactions between the different cement pastes can be seen in Figure 5. The graph shows viscosity results at midvalues of mineral admixture content at a $0.40 \mathrm{w} / \mathrm{c}$ ratio. The results based on reaction time were in the following sequence: $30 \%$ slag (the cement paste with $30 \%$ slag) $>$ OPC (the cement paste with no admixture) $>10 \%$ SF (the cement paste with $10 \%$ silica fume). The paste with silica fume began to react more quickly than the control paste, which, in turn, began to react faster than the latently hydraulic slag paste. The results of the rotational viscometer test show approximately the same trend as those of the DSR test.

When looking at each individual mineral admixture employed at various replacement levels in the preliminary tests, it was found that no trend with admixture content was shown at a $0.4 \mathrm{w} / \mathrm{c}$ ratio. This was true for all mineral admixtures except for silica fume. At a $0.40 \mathrm{w} / \mathrm{c}$ ratio, the viscosity of silica fume paste increased from $5 \%$ to $10 \%$. However, the viscosity dropped from $10 \%$ to $15 \%$. These results confirmed that as the silica fume content increases to a certain level, the plastic viscosity also increases. For the remaining mineral admixtures, a $0.5 \mathrm{w} / \mathrm{c}$ ratio was used for all viscosity tests for the different replacement levels.

The rotational viscometer test results with 3 different slag contents are shown in Figure 6. Using the rotational viscometer, it was difficult to find a trend with slag content. After discussion, the following reasons were suggested.

3.2.1. Rotational Viscometer Equipment. It is originally designed to measure the rheological properties of the asphalt binder at high temperatures $\left(135^{\circ} \mathrm{C}\right.$ and $\left.165^{\circ} \mathrm{C}\right)$. In this study, the rheological properties of cement paste were measured at $25^{\circ} \mathrm{C}$

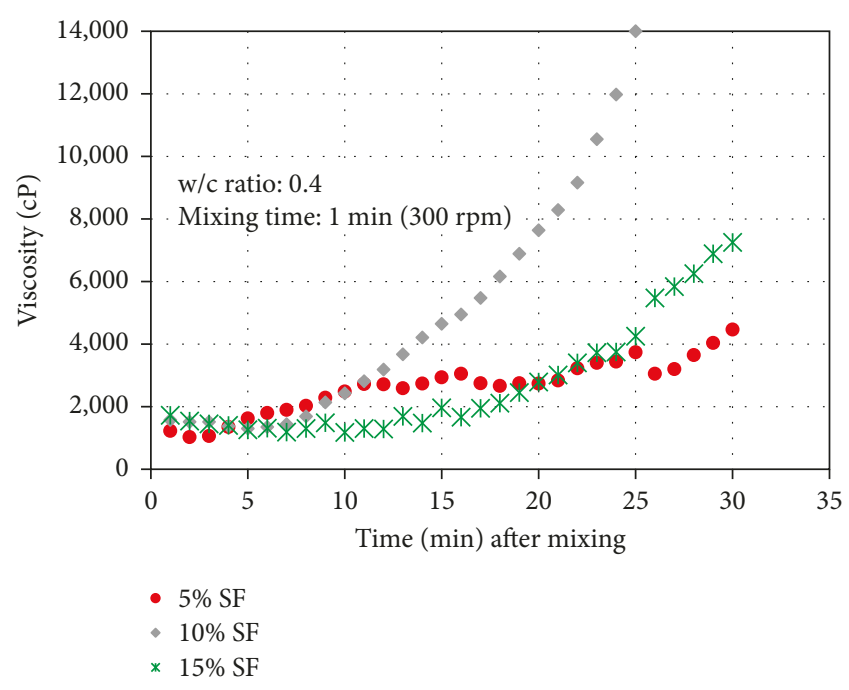

Figure 7: Viscosity with silica fume content $(0.4 \mathrm{w} / \mathrm{c}$ ratio).

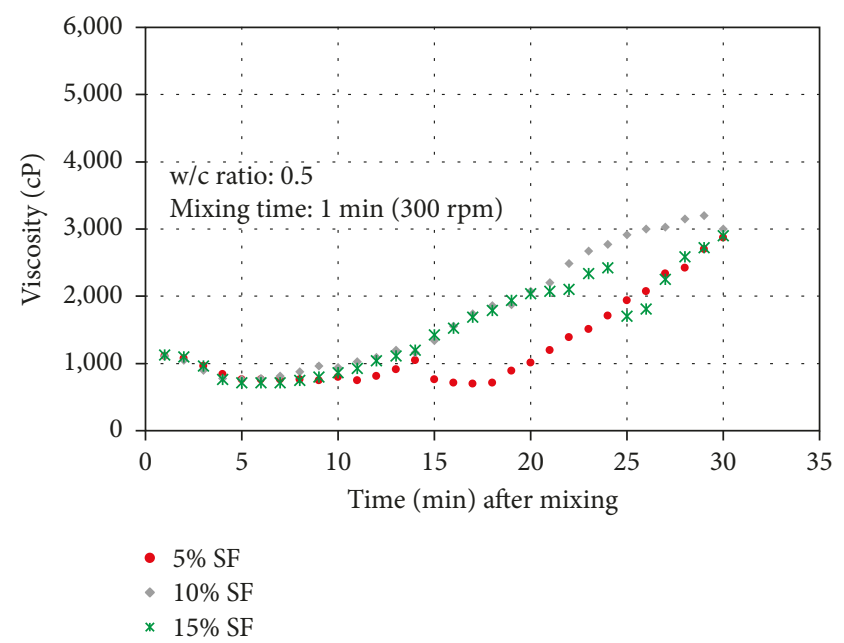

FIgURE 8: Viscosity with silica fume content $(0.5 \mathrm{w} / \mathrm{c}$ ratio).

3.2.2. Cement Paste Sample. In each test, roughly $20 \mathrm{~g}$ of cement paste was used. The calculated amount of cement paste in each test was different because of the difference of specific gravity between slag and cement. At $25^{\circ} \mathrm{C}$, the cement paste was not fluid because the asphalt binder was at $135^{\circ} \mathrm{C}$. It was very difficult to obtain the exact amount of paste in the test tubes needed for the appropriate volume.

Rotational viscometer test results with 3 different silica fume contents are shown in Figures 7 and 8. For both w/c ratios, the viscosity increased from $5 \%$ to $10 \%$ but decreased when taken up to $15 \%$.

Rotational viscometer test results with 3 different fly ash contents are shown in Figure 9. As the fly ash content increased, the viscosity decreased. Fly ash lowered the water demand in concrete. With increasing amounts of fly ash and the same w/c ratio, the higher fly ash replacement levels should have lower viscosities. With more fly ash, there were also fewer cement hydration products. 


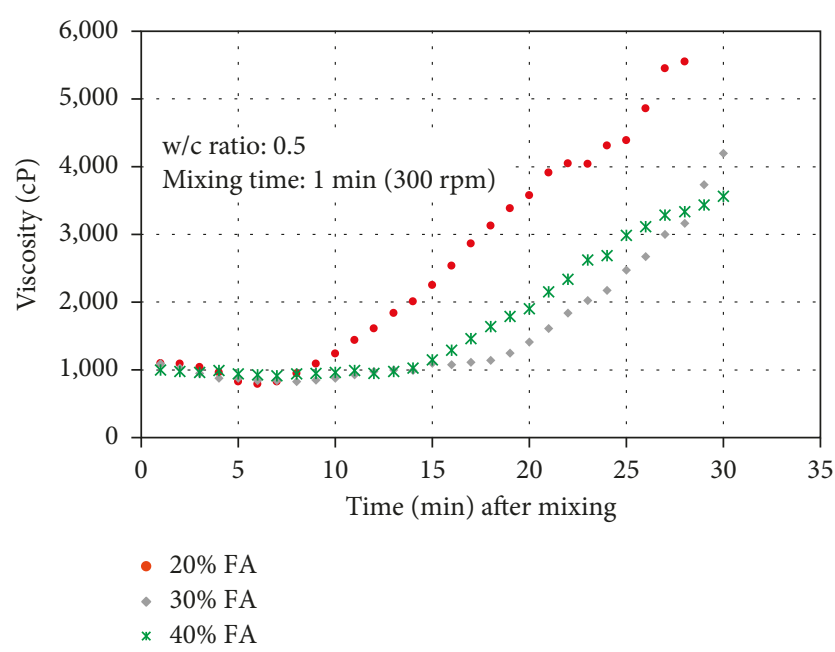

FIGURE 9: Viscosity with fly ash content $(0.5 \mathrm{w} / \mathrm{c}$ ratio).

\section{Conclusions}

Cement pastes exhibit different rheological behaviors with respect to age, mineral admixture type, and cement replacement levels. Results from testing indicated that the rotational viscometer can be used to study the flow characteristics of cement pastes with or without mineral admixtures.

(1) The data for silica fume and fly ash at a w/c ratio of 0.50 demonstrated the expected trends. For silica fume, the viscosity increased from $5 \%$ to $10 \%$ and then increased from $10 \%$ to $15 \%$. This corresponds to the effects observed in previous research, in which high amounts of silica fume lowered the plastic viscosity.

(2) For fly ash, the viscosity decreased as the amount of cement replacement increased. As the fly ash content increased, the amount of free water also increased due to the lowered water demand of fly ash. Additionally, fewer hydration products formed with lower amounts of cement in the relatively short time periods investigated.

(3) The viscosity data for slag, however, did not follow the expected trends. It was expected that an increase in the slag content would lower the viscosity of the paste due to the latent hydraulic nature of slag. With increased amounts of cement replacement, there should be lowered amounts of hydration products. In addition, high amounts of slag should lower the water demand of the paste, thus artificially increasing the $\mathrm{w} / \mathrm{c}$ ratio.

The data for the dynamic shear rheometer are imprecise at best. The expected results from DSR testing were not obtained for any of the mineral admixtures.

\section{Conflicts of Interest}

The authors declare that there are no conflicts of interest regarding the publication of this paper.

\section{References}

[1] American Concrete Institute, ACI Manual of Concrete Practice, American Concrete Institute, Farmington Hills, MI, USA, 2017.

[2] W. Chen and H. Huang, "Effect of fly ash on rheological properties of cement paste," Journal of Wuhan University of Technology, vol. 32, no. 17, pp. 186-192, 2010.

[3] J. E. Wallevik, "Rheological properties of cement paste: thixotropic behavior and structural breakdown," Cement and Concrete Research, vol. 39, no. 1, pp. 14-29, 2009.

[4] C. F. Ferraris and N. S. Martys, "Relating fresh concrete viscosity measurements from different rheometers," Journal of Research of the National Institute of Standards and Technology, vol. 108, no. 3, pp. 229-234, 2003.

[5] L. Struble and G.-K. Sun, "Viscosity of Portland cement paste as a function of concentration," Advanced Cement Based Materials, vol. 2, no. 2, pp. 62-69, 1995.

[6] K. Kovler and N. Roussel, "Properties of fresh and hardened concrete," Cement and Concrete Research, vol. 41, no. 7, pp. 775-792, 2011.

[7] L. Struble and R. Szecsy, "Rheology of Fresh Concrete," Materials for the New Millennium: Proceedings of the Fourth Materials Engineering Conference, K. P. Chong, ed., pp. 1121-1128, American Society of Civil Engineers, Washington, DC, USA, 1996.

[8] M. Bellotto, "Cement paste prior to setting: a rheological approach," Cement and Concrete Research, vol. 52, pp. 162168, 2013.

[9] P. Banfill, "The rheology of fresh cement and concrete-a review," in Proceedings of the 11th International Cement Chemistry Congress, Watt University, Durban, South Africa, May 2003.

[10] J. E. Wallevik, "Thixotropic investigation on cement paste: experimental and numerical approach," Journal of NonNewtonian Fluid Mechanics, vol. 132, no. 1-3, pp. 86-99, 2005.

[11] The Asphalt Institute, Superpave Series No. 1-Performance Graded Asphalt: Binder Specification and Testing, The Asphalt Institute, Lexington, KY, USA, 2003. 


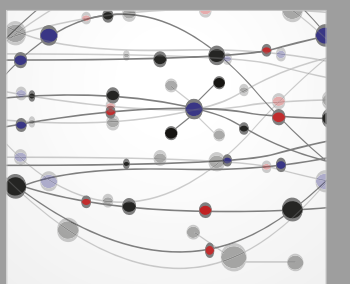

The Scientific World Journal
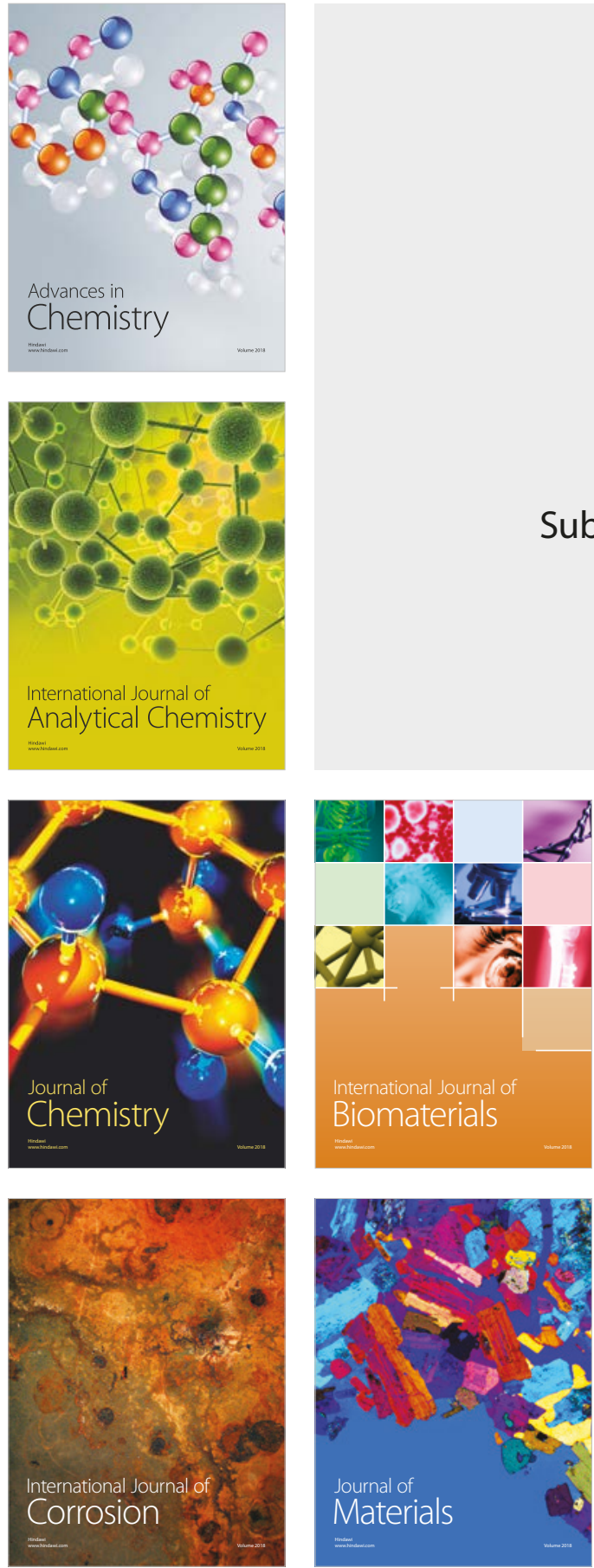

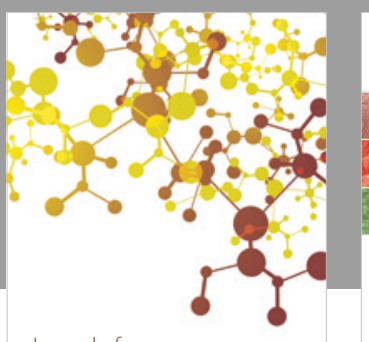

Journal of

Applied Chemistry
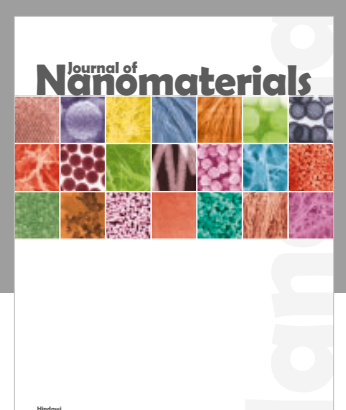

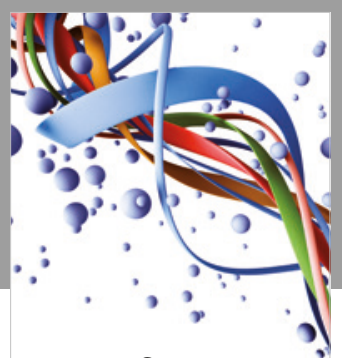

Scientifica

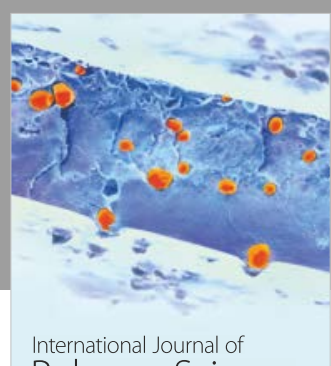

Polymer Science

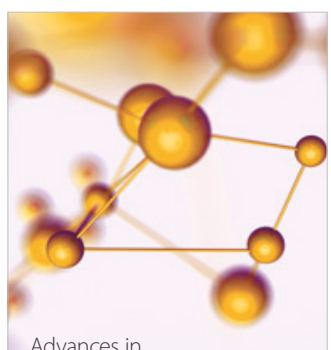

Physical Chemistry
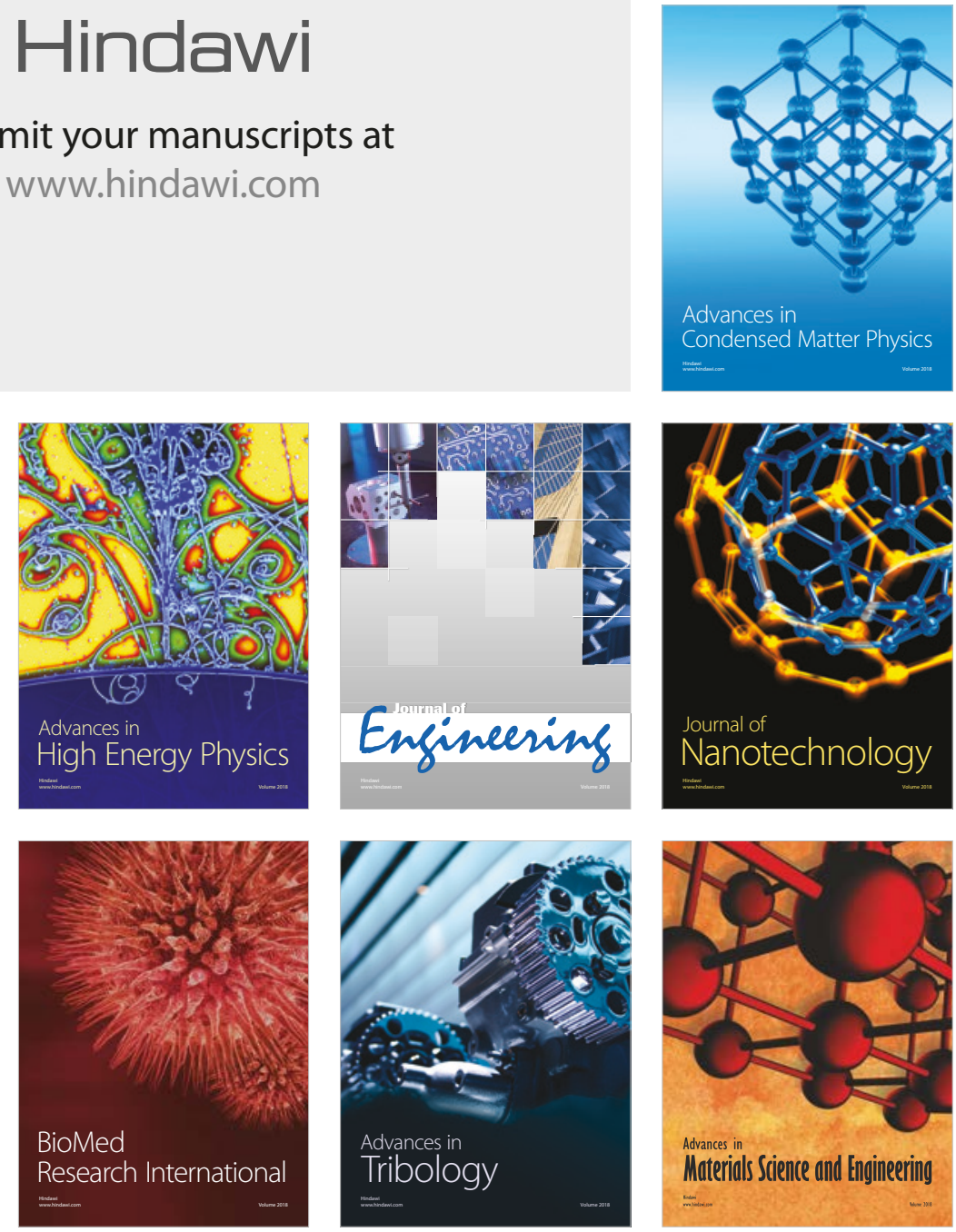